\title{
Pola Hidrodinamika di Perairan Nunukan sebagai Usulan pada Permasalahan Abrasi Pulau-pulau Kecil
}

\section{WULAN FITRY HARDHIYANTI' ${ }^{1}$, YESSI NIRWANA KURNIADI ${ }^{1}$, EVA MUSTIKASARI ${ }^{2}$, YOGI NOVIADI ${ }^{3}$}

\author{
${ }^{1}$ Jurusan Teknik Sipil Institut Teknologi Nasional \\ 2Pusat Penelitian dan Pengembangan Sumber Daya Laut dan Pesisir, Kementerian \\ Kelautan dan Perikanan \\ ${ }^{3}$ Pusat Penelitian dan Pengembangan Geologi Kelautan, Kementerian Energi dan Sumber \\ Daya Mineral \\ Email: wulanfitryh@gmail.com
}

\begin{abstract}
ABSTRAK
Perairan Nunukan yang berada di Provinsi Kalimantan Utara, merupakan salah satu wilayah terluar Indonesia yang berbatasan langsung dengan Negara Malaysia. Berada dalam wilayah terluar, Kabupaten Nunukan menyimpan banyak potensi dalam sektor kelautan dan perikanan. Sangat penting untuk menjaga zona ekonomi eksklusif pulau-pulau kecil terluar Indonesia dari abrasi. Besar abrasi yang mungkin terjadi dapat diketahui dengan melakukan analisis pemodelan mengenai hidrodinamika wilayah tersebut. Pemodelan numerik dilakukan menggunakan perangkat lunak MIKE 21 dengan modul Hydrodynamic (HD). Pemodelan yang dilakukan terdiri dari grid persegi dan mesh terstruktur. Hasil penelitian menunjukkan terdapat beberapa daerah di Kabupaten Nunukan terjadi peningkatan kecepatan arus antara 0,1625 m/s sampai 0,3 m/s yang berpotensi terjadi abrasi. Abrasi terjadi di barat daya Pulau Sebatik, Perairan Nunukan sepanjang 1.014,26 meter. Penelitian sebelumnya menunjukkan, ukuran butir di wilayah tersebut sebesar pasir kelanauan sebesar 0,01 mm. Terdapat hubungan antara kecepatan dan ukuran butir yang menyatakan wilayah tersebut memiliki potensi abrasi.
\end{abstract}

Kata kunci: hidrodinamika, pemodelan, arus, pasang surut, abrasi

\begin{abstract}
Sebatik Island is located in Nunukan sea at North Kalimantan Province. This island is one of the outermost area in Indonesia which is in border line with Malaysia. These outlying islands keep a lot of potential in marine, and fishery. It is important to keep Indonesia exclusive economic zone by protecting this outlying island from abrasion. Abrasion can be found by analyzing hydrodynamic modelling in the area. Hydrodynamic modelling is using software MIKE 21 with Hydrodynamic modules (HD). The numerical hydrodynamic modelling was consists of rectangular grid and unstructured mesh modelling. The modelling showed there are some area in Kabupaten Nunukan are has increase of current velocity between $0.1625 \mathrm{~m} / \mathrm{s}$ and $0.3 \mathrm{~m} / \mathrm{s}$ that potentially to abrasion. Abrasion occurred in the southwest of Sebatik Island, Nunukan sea along 1,014.26 meters. Based on the observation before, the grain size in the area was $0.01 \mathrm{~mm}$ sand silt. There is correlation between the current velocity and grain size in the area has potentially to abrasion.
\end{abstract}

Keywords: hydrodynamic, modelling, current, tides, abrasion 


\section{PENDAhULUAN}

Langkah mendasar dalam mewujudkan pengamanan garis pantai di Kabupaten Nunukan adalah perlu adanya informasi mengenai hidro-oseanografi di wilayah tersebut. Menurut Pariwono (2006) salah satu aspek penting untuk mengetahui dan memahami agar pengelolaan sumber daya dapat dilaksanakan dengan tepat yaitu mengetahui dinamika perairannya. Hidrodinamika di suatu perairan dapat diketahui setelah dilakukan beberapa pengamatan seperti pasang surut, batimetri dan pola arus di wilayah tersebut. Pengambilan data dilakukan pada wilayah di Kabupaten Nunukan, Kalimantan Utara tepatnya pada koordinat Utara 4,09615 Timur 117,71347. Pemodelan dilakukan dengan menggunakan rectangular grid dan unstructured mesh. Hasil pemodelan yang sudah di validasi dapat digunakan untuk analisis selanjutnya sehingga diketahui wilayah yang terdampak abrasi dilihat dari adanya peningkatan kecepatan arus.

\section{TINJAUAN PUSTAKA}

\subsection{Abrasi}

Abrasi merupakan erosi pada dasarnya. Erosi sendiri adalah proses pengikisan batuan, tanah, maupun padatan lainnya yang disebabkan oleh gerakan air, es, atau angin. Selain terkait masalah kerusakan lingkungan, kondisi di suatu wilayah juga turut mempengaruhi tingginya gelombang air laut serta tanah sehingga mengalami erosi. Abrasi sendiri memiliki 5 kelas dalam kerusakannya yaitu ringan, sedang, berat, amat berat, dan amat sangat berat.

\subsection{Arus}

Arus laut adalah suatu pergerakan massa air secara vertikal serta horizontal sehingga menuju suatu keseimbangannya dengan wilayah yang sangat luas. Arus dipengaruhi oleh beberapa faktor yaitu perbedaan permukaan air laut, angin, perbedaan temperatur, perbedaan salinitas dan kepadatan air, pasang surut, dan bentuk pantai. Arus salah satunya dipengaruhi oleh angin dan dipengaruhi oleh musim. Di Indonesia sendiri dikenal 4 musim, yaitu musim barat yang terjadi selama periode bulan Desember-Februari, musim peralihan barat ke timur yang terjadi selama periode bulan Maret-Mei, musim timur yaitu terjadi selama periode bulan JuniAgustus, dan musim peralihan timur ke barat yaitu terjadi selama periode bulan SeptemberNovember.

\subsection{Pasang Surut}

Pasang surut adalah fluktuasi muka air laut sebagai fungsi waktu karena adanya gaya tarik benda-benda di langit, terutama matahari dan bulan terhadap massa air laut di bumi. Perbedaan vertikal antara pasang tinggi dan pasang rendah disebut rentang pasang surut (tidal range). Jenis pasang surut berbeda-beda, tergantung letak wilayah tersebut. Terdapat empat jenis pasang surut yang ditunjukkan pada dimana bentuk kurva berbeda-beda dari besarnya pasang surut terhadap fungsi waktu. Jenis-jenis pasang surut anatar lain pasang surut harian ganda (semi diurnal tide), pasang surut harian tunggal (diurnal tide), pasang surut campuran condong ke harian ganda (mixed tide prevailing semidiurnal), pasang surut campuran condong ke harian tunggal (mixed tide prevailing diurnal). Pada umumnya sifat pasang surut di perairan dapat ditentukan dengan menggunakan rumus Formzahl seperti pada Persamaan 1 berikut:

$$
F=\frac{K_{1}+O_{1}}{M_{2}+S_{2}}
$$


dimana:

$O_{1} \quad=$ unsur pasang surut tunggal utama yang disebabkan oleh gaya tarik bulan,

$K_{1} \quad=$ unsur pasang surut tunggal yang disebabkan oleh gaya tarik matahari,

$M_{2} \quad$ = unsur pasang surut ganda utama yang disebabkan oleh gaya tarik bulan,

$S_{2} \quad=$ unsur pasang surut ganda utama yang disebabkan oleh gaya tarik matahari.

Nilai Formzahl ditunjukkan pada Tabel 1 berikut:

Tabel 1. Nilai Formzahl

\begin{tabular}{ccc}
\hline No. & Bilangan Formzahl & Jenis Pasang Surut \\
\hline 1 & $0,00-0,25$ & Ganda (semi diurnal) \\
\hline 2 & $0,26-1,50$ & $\begin{array}{c}\text { Campuran dengan tipe ganda yang } \\
\text { menonjol (mixed, mainly semi diurnal) }\end{array}$ \\
\hline 3 & $1,51-3,00$ & $\begin{array}{c}\text { Campuran dengan tipe tunggal yang } \\
\text { menonjol (mixed, mainly diurnal) }\end{array}$ \\
\hline 4 & $>3,00$ & Tunggal (diurna) \\
\hline
\end{tabular}

(Sumber: Pratikto et al, 1996)

\subsection{Perangkat Lunak MIKE 21}

Mike 21 adalah pemodelan terhadap pesisir dan perairan laut. Memasukkan data-data pendukung seperti data batimetri, data arus, data sungai, dan besar sedimen yang terdapat di wilayah tersebut, maka akan didapatkan hasil tinggi muka air yang terjadi, kecepatan arus, debit, dan sedimentasi yang terjadi dalam jangka waktu tertentu. Modul yang digunakan pada MIKE 21 adalah hydrodinamic module (HD). Pada hydrodynamic module terdapat persamaan yang menggambarkan aliran dan perbedaan muka air dengan Persamaan 2, Persamaan 3, Persamaan 4 berikut:

$$
\begin{gathered}
\frac{\partial \zeta}{\partial t}+\frac{\partial p}{\partial x}+\frac{\partial q}{\partial y}=\frac{\partial d}{\partial t} \\
\frac{\partial p}{\partial t}+\frac{\partial}{\partial x}\left(\frac{p^{2}}{h}\right)+\frac{\partial}{\partial y}\left(\frac{p q}{h}\right)+g h \frac{\partial \zeta}{\partial x}+\frac{g p \sqrt{p^{2}+q^{2}}}{C^{2} \cdot h^{2}}-\frac{1}{\rho_{w}}\left[\frac{\partial}{\partial x}\left(h \tau_{x x}\right)+\frac{\partial}{\partial y}\left(h \tau_{x y}\right)\right]-\Omega_{q}-f V V_{x}+\frac{h}{\rho_{w}} \frac{\partial}{\partial x}\left(p_{a}\right)=0 \\
\frac{\partial q}{\partial t}+\frac{\partial}{\partial y}\left(\frac{q^{2}}{h}\right)+\frac{\partial}{\partial x}\left(\frac{p q}{h}\right)+g h \frac{\partial \zeta}{\partial y}+\frac{g p \sqrt{p^{2}+q^{2}}}{C^{2} \cdot h^{2}}-\frac{1}{\rho_{w}}\left[\frac{\partial}{\partial y}\left(h \tau_{x x}\right)+\frac{\partial}{\partial x}\left(h \tau_{x y}\right)\right]-\Omega_{p}-f V V_{y}+\frac{h}{\rho_{w}} \frac{\partial}{\partial x y}\left(p_{a}\right)=0
\end{gathered}
$$

dimana:

$\begin{array}{ll}h(x, y, t) & =\text { kedalaman air }[\mathrm{m}], \\ d(x, y, t) & =\text { kedalaman air dalam berbagai waktu }[\mathrm{m}], \\ \zeta(x, y, t) & =\text { elevasi permukaan }[\mathrm{m}], \\ p, q(x, y, t) & =\text { flux density dalam arah } x \text { dan } y\left[\mathrm{~m}^{3} / \mathrm{s} / \mathrm{m}\right], \\ & =\text { (uh,vh); }(\mathrm{u}, \mathrm{v}), \\ C(x, y) & =\text { depth average velocity dalam arah } x \text { dan } y, \\ g & =\text { tahanan Chezy }\left[\mathrm{m}^{1 / 2} / \mathrm{s}\right], \\ f(V) & =\text { kecepatan gravitasi }\left[\mathrm{m} / \mathrm{s}^{2}\right], \\ V, V_{x}, V_{y}(x, y, t) & =\text { faktor gesekan angin, } \\ \Omega(x, y) & =\text { kecepatan angin dalam arah } x \text { dan } y[\mathrm{~m} / \mathrm{s}], \\ p_{a}(x, y, t) & =\text { parameter Coriolis }\left[\mathrm{s}^{-1}\right],\end{array}$




$$
\begin{array}{ll}
\rho_{w} & =\text { berat jenis air }\left[\mathrm{kg} / \mathrm{m}^{3}\right], \\
(x, y) & =\text { kordinat ruang }[\mathrm{m}], \\
t & =\text { waktu }[\mathrm{s}] \\
\tau_{x x}, \tau_{x y}, \tau_{y y} & =\text { komponen effective shear stress }\left[\mathrm{N} / \mathrm{m}^{2}\right] .
\end{array}
$$

\section{METODOLOGI PENELITIAN}

\subsection{Lokasi Pengamatan}

Lokasi penelitian berada di Kabupaten Nunukan, Kalimantan Utara dengan koordinat utara 4,09615 timur 117,71347 yang dilihat pada Gambar 1.

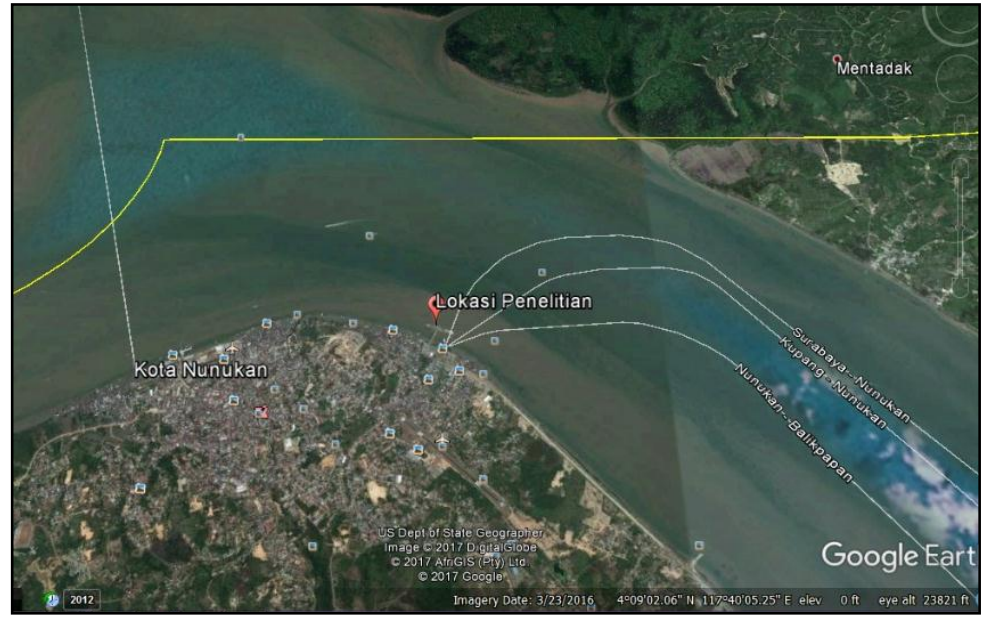

Gambar 1. Lokasi pengamatan

(Sumber: Google Earth, 2016)

\subsection{Data Penelitian}

Data yang digunakan penelitian didapat dari beberapa sumber yaitu batimetri hasil pengukuran oleh Tim Sebatik dari Pusat Penelitian dan Pengembangan Geologi Kelautan pada tahun 2005 dan data arus, pasang surut yang dilakukan Pusat Riset Kementerian Kelautan dan Perikanan pada tahun 2016. Untuk data perbandingan batimetri, digunakan data batimetri yang telah di digitasi oleh GEBCO (General Bathymetric Chart of the Oceans) yang dapat diunduh dengan data pada interval waktu tertentu.

\subsection{Batas Penelitian}

Batasan-batasan dalam penelitian ini antara lain tidak memperhitungkan tidal bore, tidak memperhitungkan perubahan garis pantai, dan tidak memperhitungkan angkutan sedimen yang terjadi.

\subsection{Alur Penelitian}

Analisis pendahuluan dilakukan dengan mengolah data-data yang diperlukan seperti batimetri. Batimetri yang digunakan pada penelitian ini terdiri dari grid series (rectangular) dan mesh generator. Wilayah yang ditinjau merupakan selat yang dikelilingi oleh pulau dan berdekatan dengan wilayah Malaysia. Data batimetri berbentuk grid series atau rectangular harus di-digitasi terlebih dahulu dengan membuat grid dengan jarak antar grid sebesar 50 meter. Setelah data batimetri sudah ter-digitasi, data tersebut di plot pada grid series MIKE 
21. Pemodelan menggunakan mesh generator, data batimetri dalam bentuk .xyz dimasukkan pada modul mesh Generator, lalu data tersebut dihubungkan antar noda menggunakan draw arc. Data batimetri telah memiliki bentuk baru dalam MIKE, selanjutnya membuat pemodelan menggunakan flow mode/sehingga dapat diketahui hidrodinamika di wilayah penelitian. Data kuat arus dan pasang surut hasil pengukuran digunakan untuk koreksi terhadap data yang dihasilkan dari pemodelan, dengan cara membandingkannya. Validasi dilakukan dengan metode RMSE (Root Mean Square Error) dan Correlation. Apabila data pemodelan telah tervalidasi oleh data pengukuran, maka pemodelan bisa digunakan untuk dasar analisis selanjutnya yaitu mengetahui wilayah yang berpotensi abrasi dengan melihat perubahan kecepatannya.

\section{PENGOLAHAN DATA DAN PEMBAHASAN}

\subsection{Data Validasi}

Pasang surut dan kecepatan arus didapat dari hasil pengukuran lapangan menggunakan tidemaster dan ADCP. Data hasil pengukuran pasang surut oleh tidemaster dilakukan dengan pengamatan 15 menit selama 22 hari. Kecepatan rata-rata perairan Nunukan tergambar dalam grafik sebaran kecepatan arus hasil pengukuran ADCP (Acoustic Doppler Current Profiler) yang ditunjukan pada Gambar 2. Terlihat bahwa kecepatan arus di perairan nunukan mengikuti pola geometri perairan yang mengarah ke timur laut-tenggara. Rata-rata kecepatan arus berkisar $40 \mathrm{~cm} /$ detik. Arah pergerakan kecepatan arus secara visual mengikuti geometri pantai.

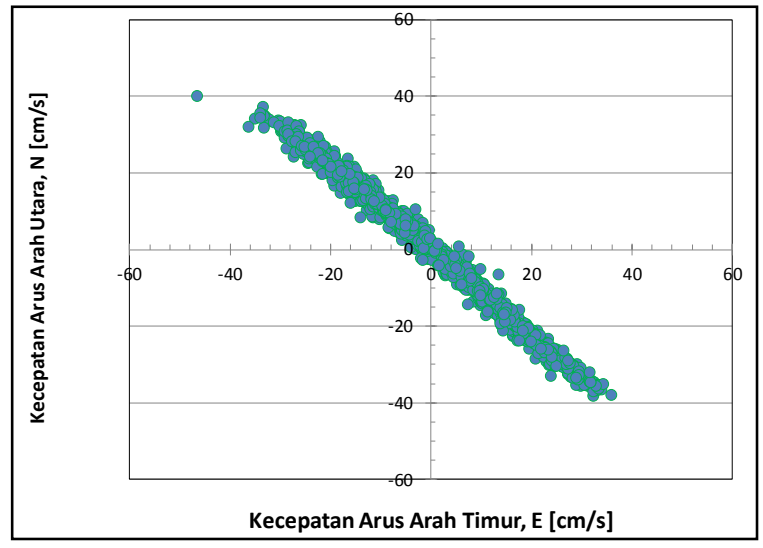

Gambar 2. Kecepatan arus rata-rata

(Sumber: Badan Penelitian dan Pengembangan Kelautan dan Perikanan, 2016)

Pada pengukuran yang dilakukan di lokasi Pengamatan oleh KKP selama 22 hari dengan interval waktu 15 menit didapat hasil dengan tenggang pasang surut diantara 2 hingga -2 yang diukur berdasarkan mean sea level yang dapat dilihat pada Gambar 3. Jenis pasang surut yang terdapat pada wilayah tinjauan adalah pasang surut condong harian ganda (semi diurnal tide) dengan periode pasang surut rata-rata 12 jam. 


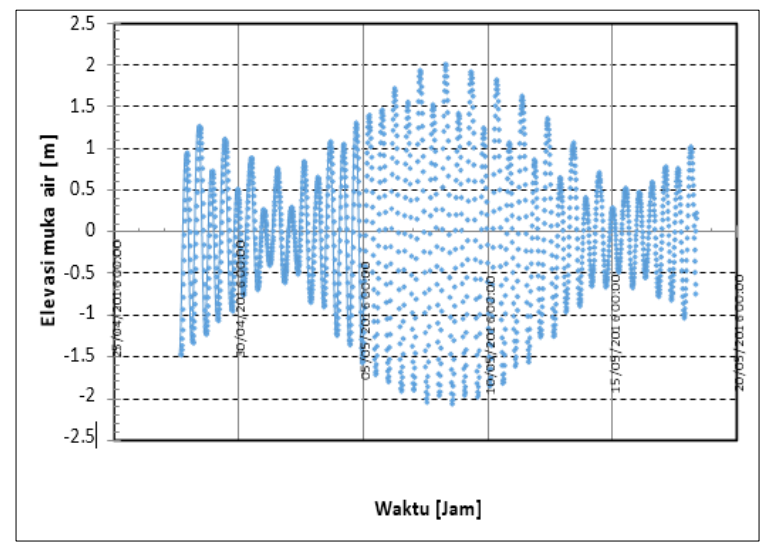

Gambar 3. Pasang surut pengamatan tidemaster

(Sumber: Badan Penelitian dan Pengembangan Kelautan dan Perikanan, 2016)

\subsection{Perbandingan Pemodelan dengan Data Validasi}

Hasil output pemodelan harus tervalidasi terlebih dahulu sebelum mendapatkan pasang surut terprediksi agar data pemodelan sesuai data yang ada di lapangan. Validasi dilakukan dengan melakukan perbandingan hasil yang didapat dari pengukuran terhadap pemodelan dengan dua metode, yakni RMSE dan Correlation. Pemodelan 1 merupakan penamaan dari pemodelan yang menggunakan batimetri dengan modul grid series atau rectangular, sedangkan untuk pemodelan 2 adalah penamaan untuk pemodelan dengan menggunakan batimetri dengan modul mesh generator. Berikut hasil perbandingan antara hasil pengukuran dan pemodelan pada Tabel $\mathbf{2}$.

Tabel 2. Nilai RMSE dan Correlation

\begin{tabular}{|c|c|c|c|c|c|c|c|c|}
\hline \multirow[b]{2}{*}{ Pemodelan } & \multirow[b]{2}{*}{$\begin{array}{l}\text { Manning } \\
{\left[\mathrm{m}^{1 / 2} / \mathrm{s}\right]}\end{array}$} & \multirow[b]{2}{*}{$\begin{array}{c}\text { Eddy } \\
\text { Viscosity } \\
{\left[\mathrm{m}^{2} / \mathrm{s}\right]}\end{array}$} & \multicolumn{3}{|c|}{ RMSE } & \multicolumn{3}{|c|}{ Correlation } \\
\hline & & & $\begin{array}{c}\text { Pasang } \\
\text { Surut } \\
\text { [m] }\end{array}$ & $\begin{array}{c}\text { Kecepatan } \\
\text { Arah U } \\
\text { [m/s] }\end{array}$ & $\begin{array}{c}\text { Kecepatan } \\
\text { Arah V } \\
{[\mathrm{m} / \mathrm{s}]}\end{array}$ & $\begin{array}{c}\text { Pasang } \\
\text { Surut } \\
\text { [m] }\end{array}$ & $\begin{array}{c}\text { Kecepatan } \\
\text { Arah U } \\
{[\mathrm{m} / \mathrm{s}]}\end{array}$ & $\begin{array}{c}\text { Kecepatan } \\
\text { Arah V } \\
{[\mathrm{m} / \mathrm{s}]}\end{array}$ \\
\hline 1 & 23 & 0 & 1,1119 & 0,1641 & 0,1758 & 0,0021 & 0,0085 & 0,0247 \\
\hline 1 & 28 & 0 & 1,1073 & 0,1638 & 0,1758 & 0,6018 & 0,0037 & 0,0223 \\
\hline 1 & 32 & 0 & 1,0569 & 0,1579 & 0,1749 & 0,0542 & 0,1198 & 0,1087 \\
\hline 1 & 23 & 0,22 & 1,0514 & 0,1641 & 0,1758 & 0,0652 & 0,0078 & 0,0206 \\
\hline 1 & 28 & 0,22 & 1,0549 & 0,1638 & 0,1758 & 0,0584 & 0,0044 & 0,0234 \\
\hline 1 & 32 & 0,22 & 1,0568 & 0,1638 & 0,1749 & 0,0548 & 0,0022 & 0,0266 \\
\hline 2 & 23 & 0 & 0,4232 & 0,1883 & 0,1995 & 0,9852 & 0,4597 & 0,4691 \\
\hline 2 & 28 & 0 & 0,3398 & 0,1913 & 0,1986 & 0,9869 & 0,5514 & 0,5451 \\
\hline 2 & 32 & 0 & 0,3857 & 0,1941 & 0,1985 & 0,9871 & 0,6071 & 0,6025 \\
\hline 2 & 23 & 0,22 & 0,4230 & 0,1882 & 0,1994 & 0,9852 & 0,4697 & 0,4603 \\
\hline 2 & 28 & 0,22 & 0,3996 & 0,1911 & 0,1984 & 0,9869 & 0,5522 & 0,5460 \\
\hline 2 & 32 & 0,22 & 0,3888 & 0,1939 & 0,1982 & 0,9873 & 0,6082 & 0,6036 \\
\hline
\end{tabular}

Dari hasil pada Tabel 2, digunakan hasil perbandingan pemodelan 2 (mesh generator) dengan nilai Manning $32 \mathrm{~m}^{1 / 2} / \mathrm{s}$ dan Eddy Viscosity $0,22 \mathrm{~m}^{2} / \mathrm{s}$, karena memiliki nilai RMSE yang rendah sebesar 0,3888 dan nilai correlation sebesar 0,9873. Pada Gambar 4 terlihat data hasil pengukuran dan data hasil pemodelan dengan pasang surut, Gambar $\mathbf{5}$ data hasil pengukuran dan data hasil pemodelan untuk nilai kecepatan arus terhadap arah $U$ (barat-timur) dan arus terhadap arah V (utara-selatan). 


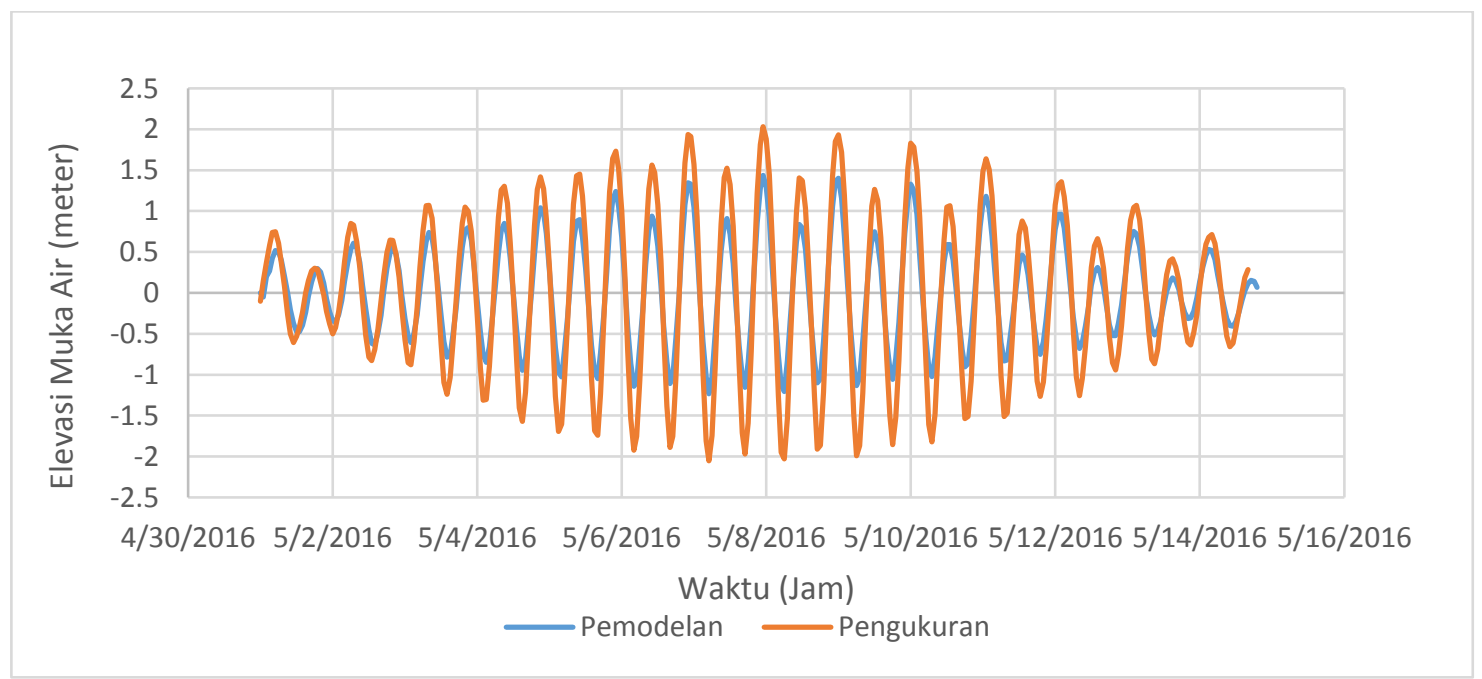

Gambar 4. Perbandingan pasang surut hasil pengamatan dan pemodelan

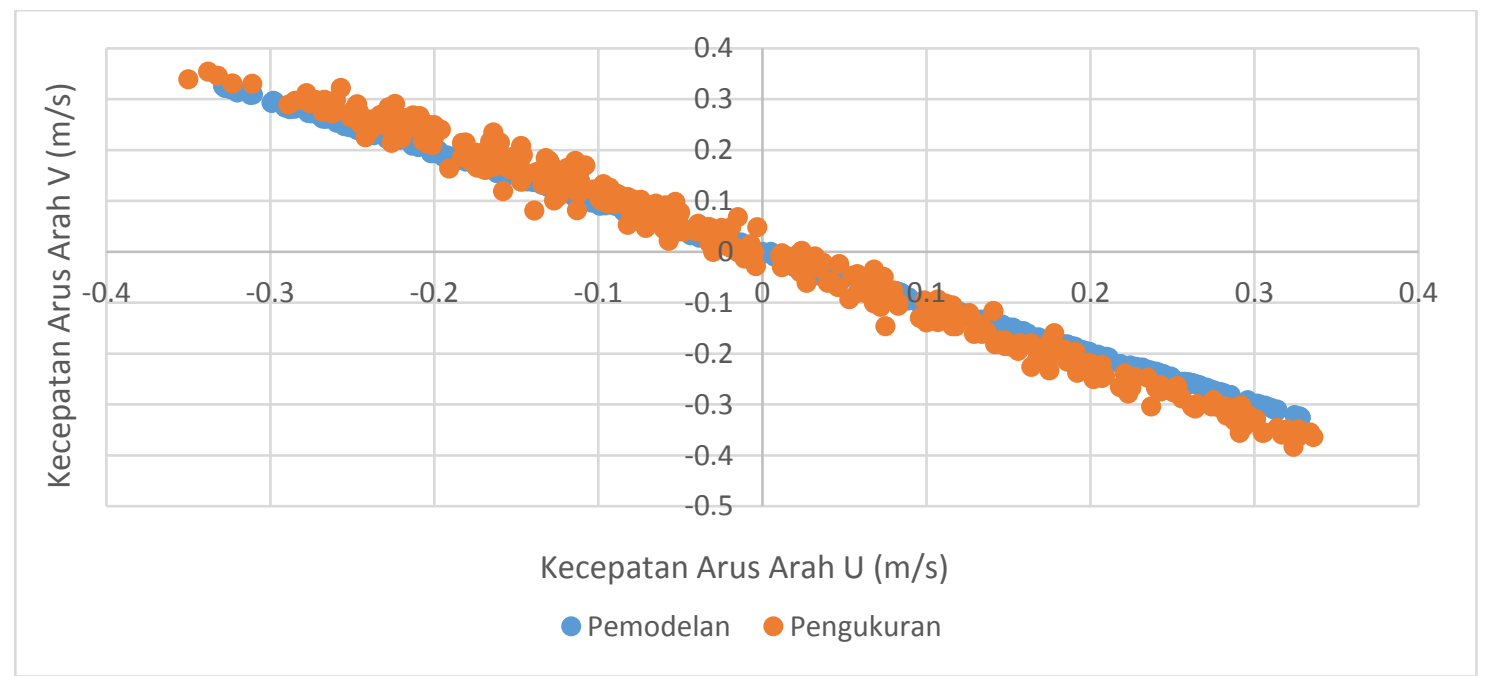

Gambar 5. Perbandingan kecepatan arus pemodelan dan pengamatan

\subsection{Analisa Kecepatan Arus dan Pasang Surut Pemodelan}

Setelah dilakukan validasi dan memilih pemodelan dengan koefisien Manning $32 \mathrm{~m} / 2 / \mathrm{s}$ dan Eddy Viscosity $0,22 \mathrm{~m}^{2} / \mathrm{s}$ dilakukan dalam interval waktu 60 hari dimulai pada tanggal 15 Mei hingga 15 Juli (dua bulan). Hasil pemodelan 2 (menggunakan batimetri hasil mesh generator) menunjukan terjadi peningkatan kecepatan arus di beberapa titik hingga time step ke 720 . Pada Gambar $\mathbf{6}$ terlihat hasil pemodelan pasang surut dengan satuan $\mathrm{m}$ dengan pergerakan yang ditunjukkan oleh vektor. Pasang surut pada wilayah tinjauan memiliki interval $0,8 \mathrm{~m}$ sampai 1,5 m. Gambar 7 terlihat kecepatan arus dalam arah U (barat-timur) memiliki besar antara $-0,5 \mathrm{~m} / \mathrm{s}$ sampai $0,8 \mathrm{~m} / \mathrm{s}$. Pada Gambar 8 ditunjukkan kecepatan arus dalam arah V (utara-selatan) dengan $-0,25 \mathrm{~m} / \mathrm{s}$ sampai $0,8 \mathrm{~m} / \mathrm{s}$. 


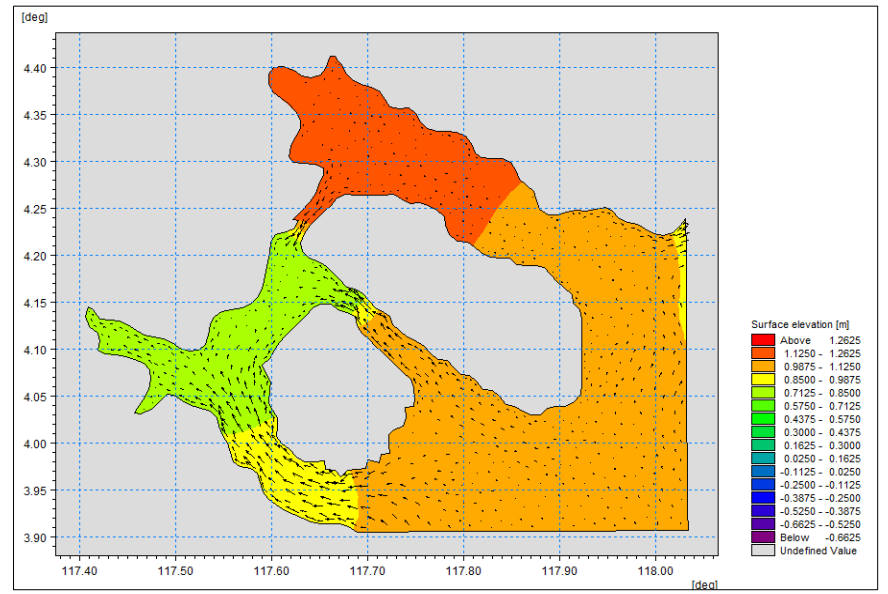

Gambar 6. Hasil output pasang surut

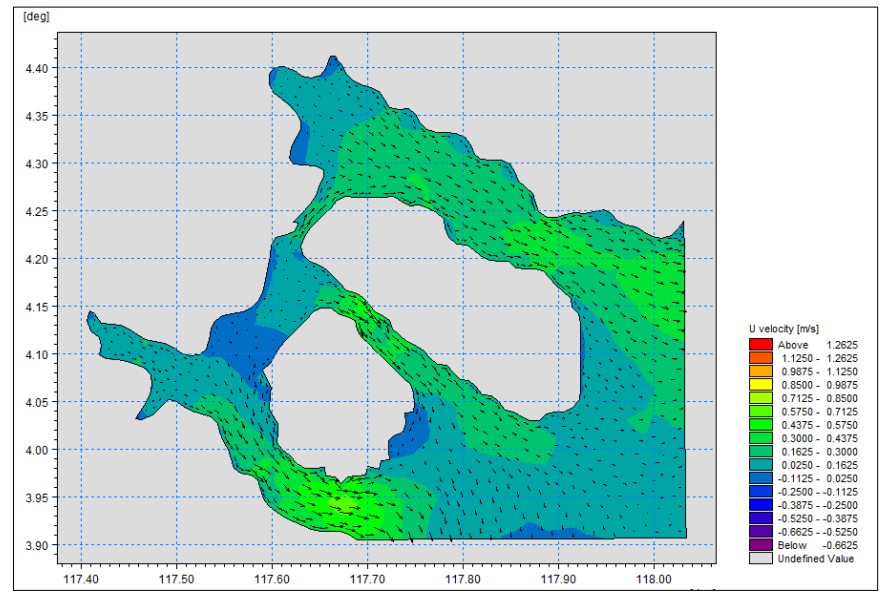

Gambar 7. Hasil kecepatan arus arah U

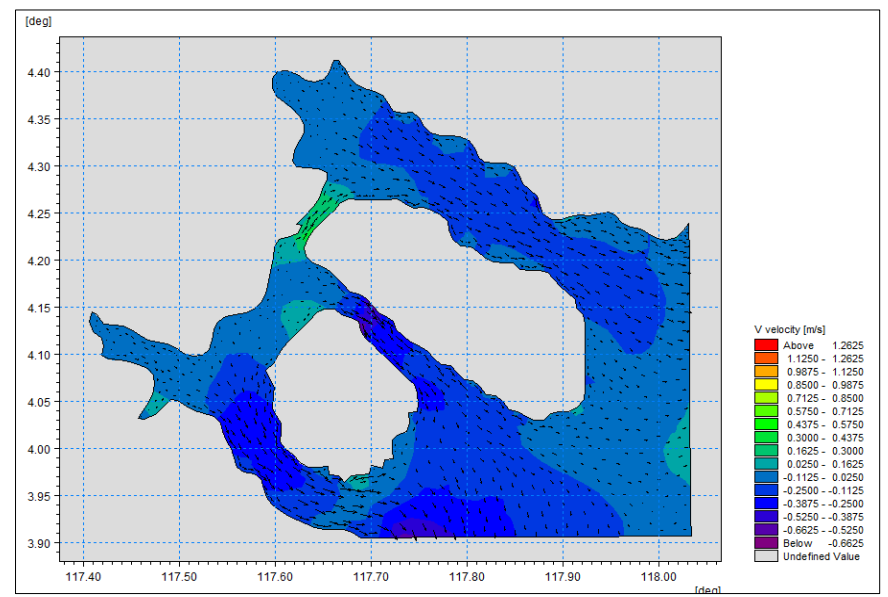

Gambar 8. Hasil kecepatan arus arah V

\subsection{Pasang Surut Purnama dan Pasang Surut Perbani}

Kondisi pasang surut purnama terjadi pada tanggal 7 Mei 2016, sedangkan pasang surut perbani terjadi pada tanggal 14 Mei 2016. Pada Gambar 9 saat kondisi pasang surut purnama, pasang surut bergerak dari arah tenggara dan timur menuju barat laut (selat). Saat kondisi surut purnama terlihat pada Gambar $\mathbf{1 0}$ terjadi perbedaan arah pasang surut yaitu menuju tenggara dan timur. Tinggi pasang surut pada kondisi purnama berkisar 1,5 meter. 
Kondisi pasang surut perbani terjadi pada tanggal 14 Mei dimana terlihat pasang perbani pada Gambar 11 dan surut perbani pada Gambar 12. Pada saat kondisi menuju pasang perbani, arah pasang surut bergerak dari arah tenggara dan timur menuju barat laut, namun saat kondisi surut perbani, arah pasang surut bergerak ke menuju timur dan tenggara. Tinggi pasang surut sekitar 0,5 meter. Jenis pasang surut pada perairan ini adalah (semi diurnal tide) dengan periode pasang surut rata-rata 12 jam.

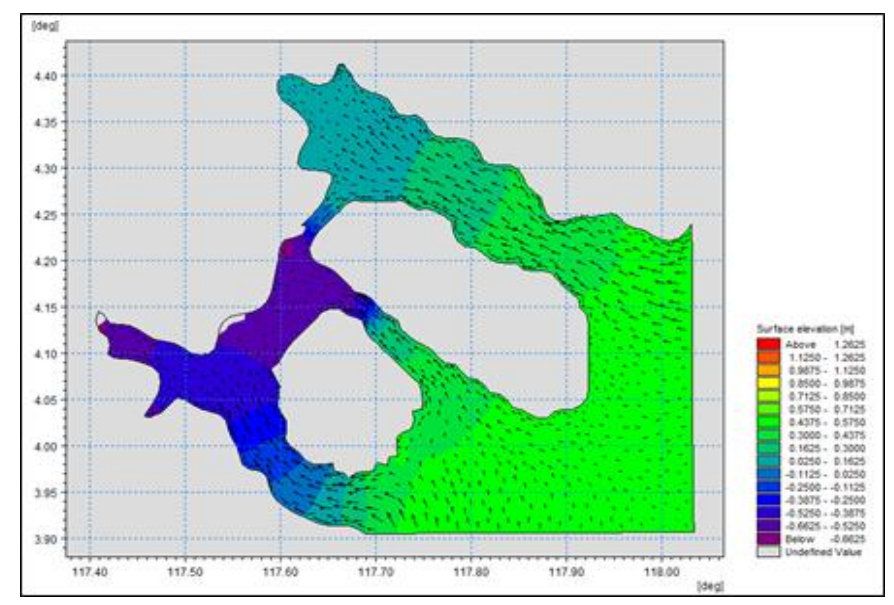

Gambar 9. Kondisi pasang purnama

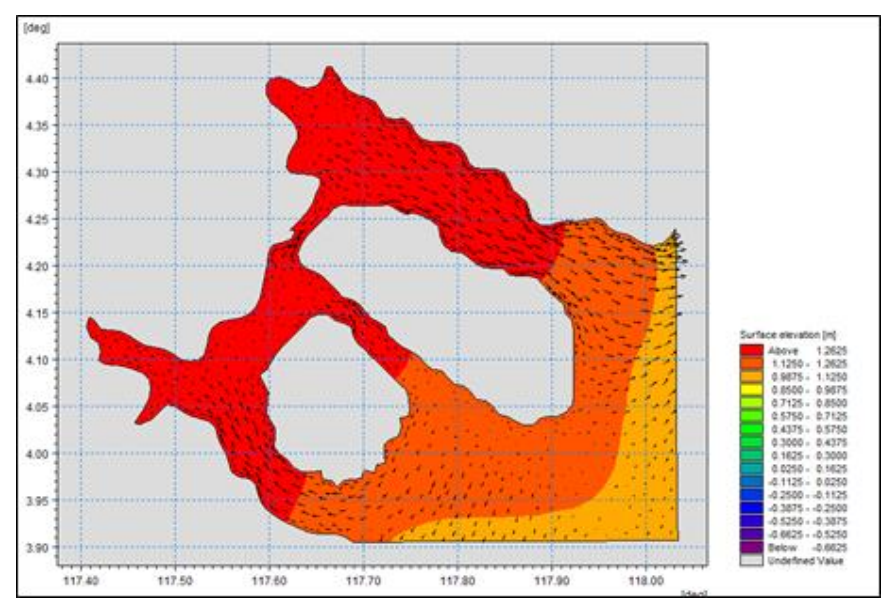

Gambar 10. Kondisi surut purnama

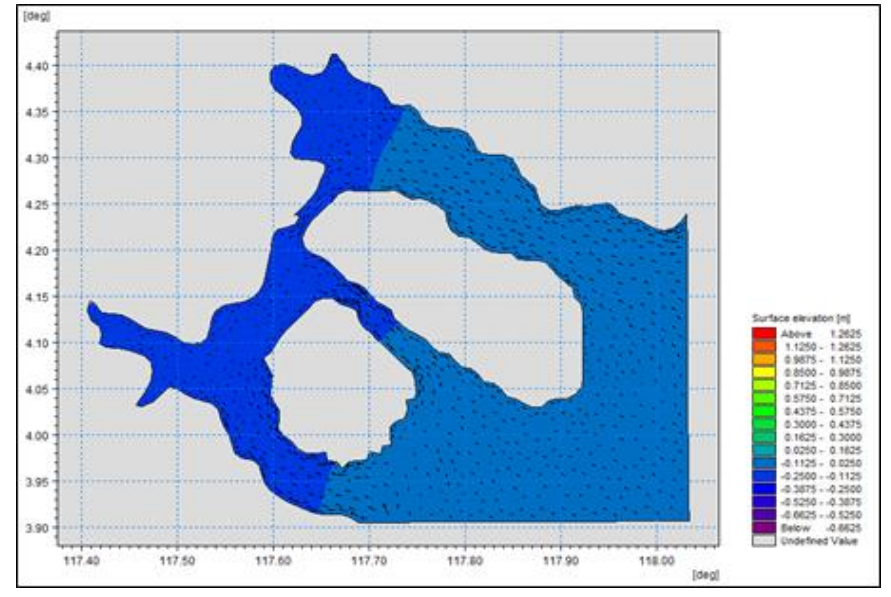

Gambar 11. Kondisi pasang perbani 


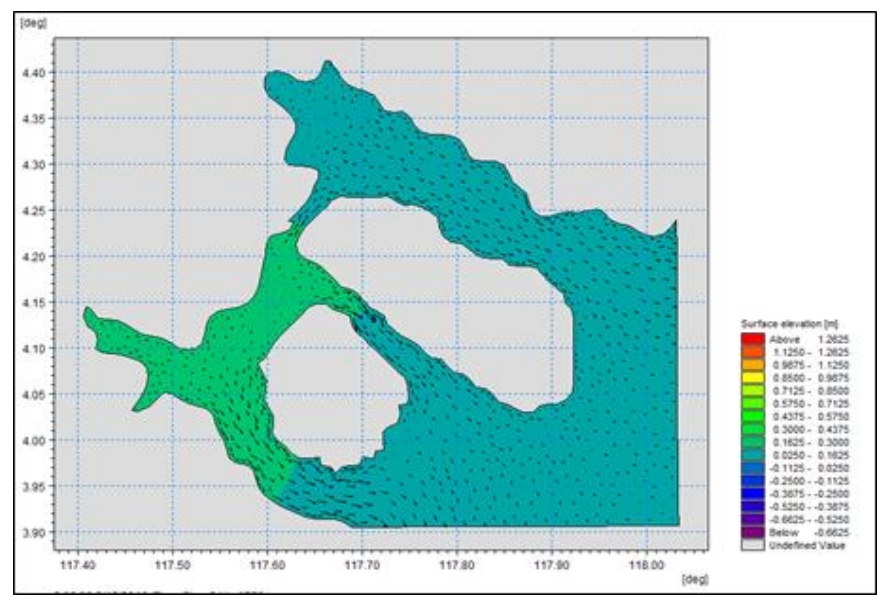

Gambar 12. Kondisi surut perbani

\subsection{Wilayah Berpotensi Abrasi}

Dilihat dari output hasil pemodelan yang dilakukan terhadap wilayah tinjauan, beberapa wilayah di Kabupaten Nunukan mengalami peningkatan kecepatan arus. Kecapatan arus pada pemodelan dengan time step ke-0 memperlihatkan kecepatan arus berkisar antara -0,2500 $\mathrm{m} / \mathrm{s}$ sampai $-0,1125 \mathrm{~m} / \mathrm{s}$ yang terlihat pada Gambar 13. Peningkatan terlihat pada Gambar 14 dengan time step ke-360 kecepatan arus meningkat berkisar antara 0,0250 m/s sampai 0,4375 m/s, sedangkan pada Gambar 15 dengan time step ke-720, kecepatan relatif sama terhadap time step sebelumnya yakni antara 0,0250 m/s sampai 0,4375 m/s. Dalam hal ini, perlu adanya peningkatan pengamanan terhadap garis pantai pada wilayah yang mengalami peningkatan kecepatan arus yang dapat dilihat pada Gambar 16. Abrasi terlihat terjadi di Barat Daya Pulau Sebatik, Perairan Nunukan pada titik X 117 ${ }^{\circ} 42^{\prime} 36^{\prime \prime}$ Y $4^{\circ} 9^{\prime} 144^{\prime \prime}$ ' hingga X

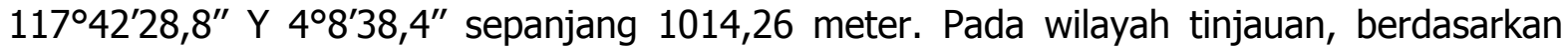
penelitian dari Tim Sebatik Pusat Penelitian dan Pengembangan Geologi Kelautan, wilayah tersebut memiliki jenis tanah lanau kepasiran. Ukuran butir lanau kepasiran dapat diketahui ukuran butirnya berdasarkan jenis tanahnya menurut AASHTO (American Association of Highway and Trasportation Officials) dalam buku M. Das (1995). Diketahui ukuran butir tanah lanau kepasiran memiliki besar butir 0,01 mm atau $10^{-5} \mathrm{~m}$. Menurut Dronkers (2005) dalam bukunya berjudul Dynamics of Coastal Systems, terdapat hubungan antara besar butir dengan kecepatan arus sehingga dapat diketahui kemungkinan terjadinya erosi ataupun abrasi. Pada wilayah tinjauan diketahui kecepatan arus sebesar antara 0,0250 m/s sampai $0,4375 \mathrm{~m} / \mathrm{s} \mathrm{m} / \mathrm{s}$ dengan ukuran butir $10^{-5} \mathrm{~m}$, pada grafik terlihat wilayah tersebut berpotensi abrasi.

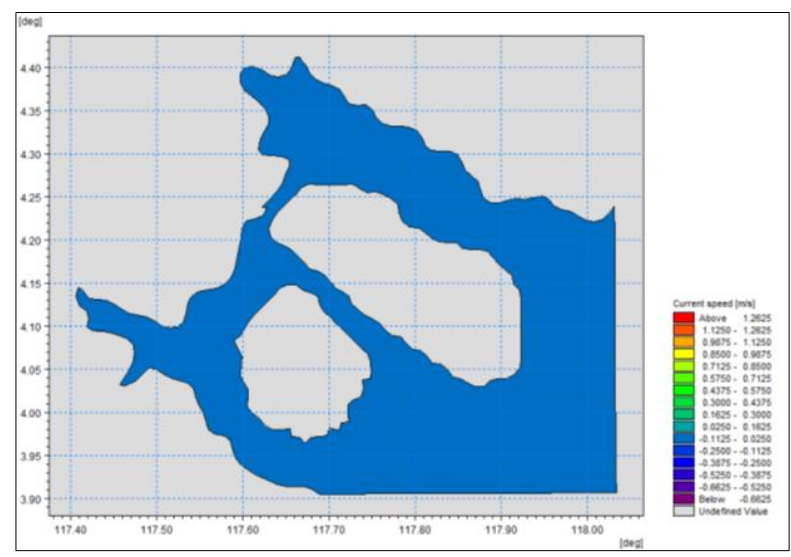

Gambar 13. Kecepatan arus pada time step 0

Reka Racana - 67 


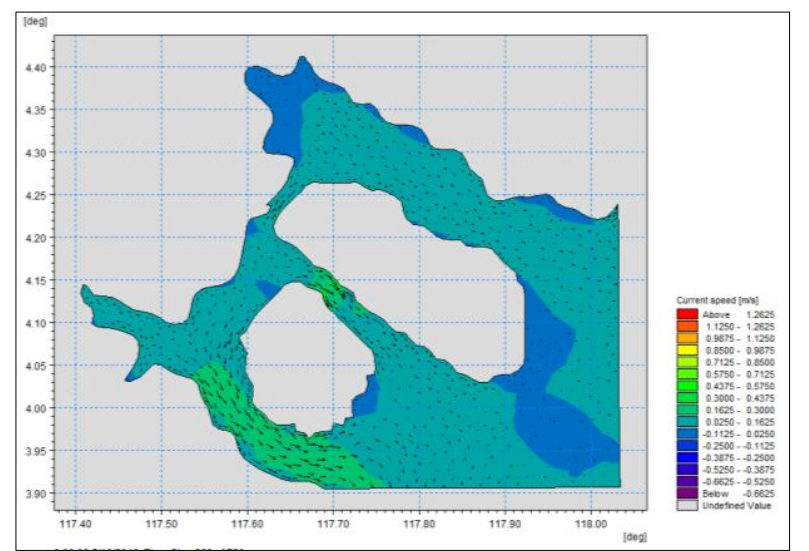

Gambar 14. Kecepatan arus pada time step 360

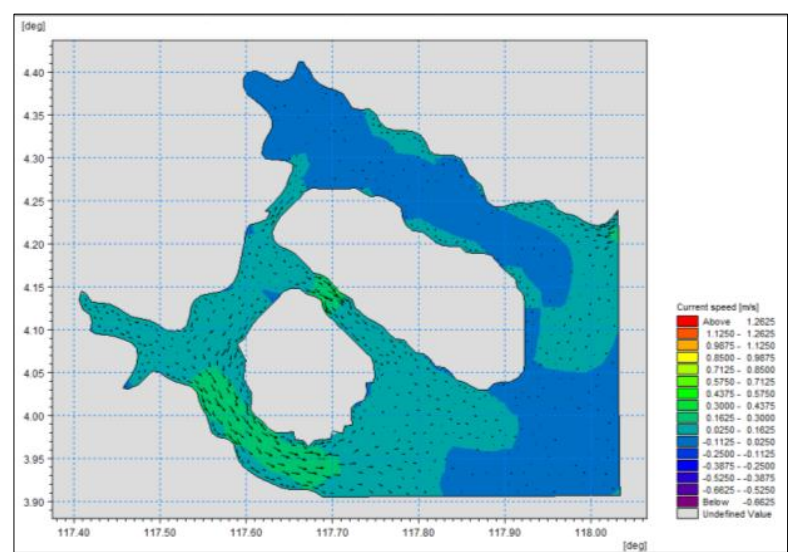

Gambar 15. Kecepatan arus pada time step 720

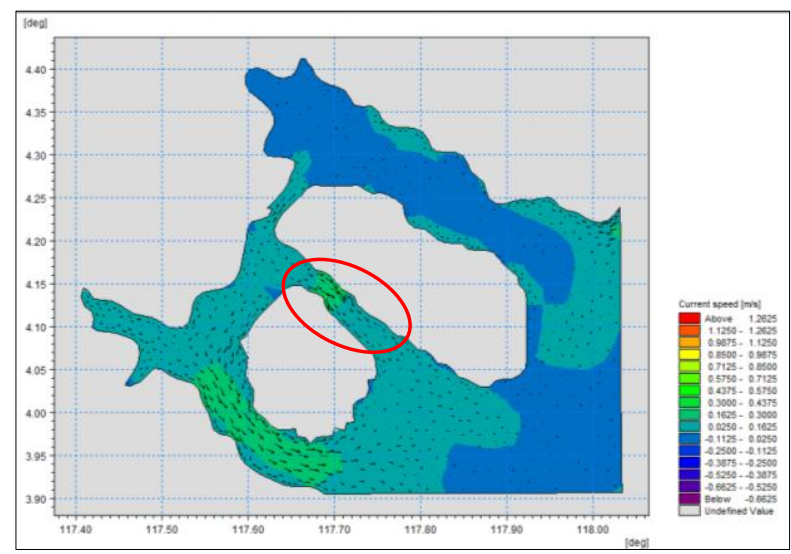

Gambar 16. Wilayah berpotensi abrasi

\section{KESIMPULAN DAN SARAN}

\subsection{Kesimpulan}

Berdasarkan hasil penelitian yang telah dilakukan pada Perairan Nunukan, Kalimantan Utara, dihasilkan kesimpulan bahwa hidrodinamika Perairan Nunukan dibangkitkan oleh pasang surut karena wilayah tinjauan berada di selat, pasang Surut pemodelan yang sebelumnya telah dilakukan validasi menggunakan RMSE dan Correlation memiliki ketinggian antara $-1,5$ meter hingga 1,5 meter, besar kecepatan arus pada titik tinjauan yang bergerak timur laut- 
tenggara, dan beberapa wilayah di Perairan Nunukan mengalami peningkatan kecepatan arus diantara $0,0250 \mathrm{~m} / \mathrm{s}$ sampai $0,4375 \mathrm{~m} / \mathrm{s}$. Wilayah yang terdampak abrasi memiliki jenis tanah lanau pasiran dengan ukuran butiran sebesar $0,1 \mathrm{~mm}$ sehingga didapat bahwa wilayah tinjauan berpotensi abrasi.

\subsection{Saran}

Data batimetri yang digunakan sebaiknya memiliki skala yang lebih kecil, sehingga dapat diperoleh grid yang lebih rapat agar hasil pemodelan grid menjadi lebih teliti, mempertimbangkan pengaruh sedimentasi pada penelitian selanjutnya, mempertimbangkan pengaruh sungai-sungai yang berada di sekitar perairan dan menganalis perubahan garis pantai dengan penggunaan bangunan pelindung pantai untuk mengatasi abrasi yang mungkin terjadi pada wilayah yang berpotensi terdampak abrasi.

\section{UCAPAN TERIMA KASIH}

Pusat Penelitian dan Pengembangan Sumberdaya Laut dan Pesisir (P3SDLP), Badan Penelitian dan Pengembangan Kelautan Perikanan, Kementerian Kelautan dan Perikanan, Pusat Penelitian dan Pengembangan Geologi Kelautan, Badan Penelitian dan Pengembangan Energi Sumber Daya Mineral, Kementrian Energi Sumber Daya dan Mineral.

\section{DAFTAR RUJUKAN}

Badan Penelitian dan Pengembangan Kelautan dan Perikanan. (2016). Laporan Akhir Nunukan. Jakarta: Kementerian Kelautan dan Perikanan.

Dronkers, Job. (2005). Dynamics of Coastal System. Singapore: World Scientific Publishing Co. Pte. Ltd.

Google, US Dept of State Geographer, AfriGis (Pty). Ltd., Digital Globe. (2017, August 25). Google Earth Pro. Dipetik dari Google Earth: https://www.google.com/maps/@4.1530244,117.67254,12793m/data=!3m1!1e3

Das, B.M. (1995). Mekanika Tanah Jilid I. Jakarta: Erlangga.

Pusat Penelitian dan Pengembangan Geologi Kelautan. (2005). Laporan Akhir Perairan Sebatik Kabupaten Nunukan Kalimantan Timur. Bandung: Badan Geologi Kementerian Energi dan Sumber Daya Mineral.

Pratikto, W.A; Armono, H.D; Suntoyo. (1996). Perencanaan Fasilitas Pantai dan Laut. Yogyakarta: BPFE. 